\title{
Metastatic Thyroid Gland Follicular Carcinoma
}

National Cancer Institute

\section{Source}

National Cancer Institute. Metastatic Thyroid Gland Follicular Carcinoma. NCI Thesaurus. Code C156099.

A follicular carcinoma that arises from the thyroid gland and has metastasized to another anatomic site. 